\title{
Construcción de un prototipo de silla de ruedas motorizada de bajo costo para personas con lesión medular
}

\author{
J. Andrés Sandoval Bringas, Mónica A. Carreño León, \\ Miguel A. Espiritu Jimenez, Israel Durán Encinas, Aarón Chávez \\ Universidad Autónoma de Baja California Sur, \\ Departamento Académico de Sistemas Computacionales, B.C.S., \\ México \\ \{mcarreno, sandoval, mespiritu, iduran, achavez\}@uabcs.mx
}

\begin{abstract}
Resumen. La atención a los discapacitados ha sido un tema de interés a las diferentes áreas de la ciencia y tecnología. El desarrollo de nuevas tecnologías enfocadas a la discapacidad, es de vital importancia ya que permite mejorar la calidad de vida y la incorporación a la sociedad. En este artículo se presenta el desarrollo de un dispositivo electrónico adaptado a una silla de ruedas motorizada, el cual permite que una persona con alguna discapacidad motora, en particular con lesión medular, pueda desplazarse dirigiendo la silla, por medio de las inclinaciones de la cabeza detectadas en un acelerómetro implantado en un auricular, y/o a través de comandos de voz, mediante una aplicación móvil desarrollada para dispositivos que cuenten con el sistema operativo Android.
\end{abstract}

Palabras clave: Discapacidad, discapacidad motriz, silla de ruedas motorizada.

\section{Introducción}

La movilidad es una de las actividades básicas de la vida cotidiana que reflejan la interacción del organismo humano con el entorno. Las dificultades para caminar, moverse o desplazarse están estrechamente relacionadas con la forma en la que está organizado el ambiente inmediato y si es accesible favorece la autonomía personal y la participación en la vida cívica, y es esencial para incorporarse a los servicios de educación y de salud, así como al mercado de trabajo; mientras que uno no accesible introduce barreras que limitan tanto la participación como la inclusión social de los individuos [1].

En México, 5 millones 739 mil personas declararon tener alguna discapacidad, lo que representa $5.1 \%$ de la población total [2]. La dificultad más frecuente entre la población con discapacidad es la relacionada con la movilidad, ya que el $58 \%$ de las personas de este grupo poblacional señala tener limitación para caminar o moverse [2]. No existen estadísticas oficiales acerca de la lesión medular específicamente, pero se sabe que pertenecen a esta clasificación. Éstas son lesiones graves que ocasionan una pérdida de la función motora y sensitiva por lesión en las estructuras nerviosas de la médula espinal, que pueden ocasionar fatiga y debilidad en brazos y piernas, por lo que 
es necesario asistir a los pacientes diagnosticados con lesión medular, en las actividades de la vida diaria básicas, lo cual tiene una repercusión personal, social y económica para el paciente y su familia [6].

El desarrollo de nuevas tecnologías enfocadas a la discapacidad, es de vital importancia ya que el uso de algún instrumento, dispositivo o software, proporciona al individuo cierta autonomía al realizar sus actividades, mejorando su calidad de vida e incorporándolo a la sociedad. Según estadísticas de la organización mundial de la salud (OMS), en la mayoría de países de ingresos bajos o medianos, solo entre el $5 \%$ y el $15 \%$ de las personas que necesitan dispositivos y tecnologías de apoyo tienen acceso a ellos, esto se debe a una producción escasa y a los costos elevados [3]. Por otro lado, la cantidad de gente que necesita desplazarse con ayuda de algún dispositivo está incrementándose continuamente, y las inversiones que realizan las casas comerciales para la producción de materiales, tanto de hardware como de software, son mínimas, y tienen que ser las instituciones públicas o privadas quienes se encarguen de ellas [11].

Considerando lo anterior, y para contribuir en actividades que mejoren la calidad de vida de las personas con discapacidad y la inclusión social, se ha desarrollado un prototipo de silla de ruedas de bajo costo, el cual puede ser controlado a través de comandos de voz y/o con inclinaciones de la cabeza, como solución económica para personas con alguna discapacidad motora, en particular con lesión medular.

\section{Marco teórico}

\subsection{Discapacidad}

El fenómeno de la discapacidad siempre ha acompañado a los seres humanos. Las personas con discapacidad "son aquellas que tienen una o más deficiencias físicas, mentales, intelectuales o sensoriales y que al interactuar con distintos ambientes del entorno social pueden impedir su participación plena y efectiva en igualdad de condiciones a las demás" [2]. Existen varios tipos de discapacidad, como los que afectan: la audición, la vista, el movimiento, el razonamiento, la memoria, el aprendizaje, la comunicación, la salud mental y las relaciones sociales [4]. En las últimas décadas, la atención a las personas con discapacidad se ha incrementado considerablemente debido a la promoción de los derechos humanos de los grupos más vulnerables y al posible aumento en el mediano y largo plazo de la presencia de discapacidad entre la población, como consecuencia del envejecimiento demográfico y la transición epidemiológica en las que se encuentra inmerso gran parte del mundo [2].

\subsection{Discapacidad motriz}

La discapacidad motriz es una condición de vida que afecta el control y movimiento del cuerpo. Los principales problemas que puede generar la discapacidad motriz son varios, entre ellos se pueden mencionar: movimientos incontrolados, dificultades de coordinación, alcance limitado, fuerza reducida, habla no inteligible, dificultad con la motricidad fina y gruesa, mala accesibilidad al medio físico [5]. Esta discapacidad se presenta cuando existen alteraciones en los músculos, huesos, articulaciones o medula espinal, así como por alguna afectación del cerebro en el área motriz impactando en la 
movilidad de la persona. Algunas veces no es visible y en otras se requiere de apoyos especiales tales como: aparatos ortopédicos, bastón, muletas, andadera o silla de ruedas, ortesis o prótesis.

La cuadriplejía y la paraplejía son resultado de lesiones en la médula espinal. La médula espinal es el camino que los mensajes usan para viajar entre el cerebro y las diferentes partes del cuerpo y está rodeada por anillos de hueso llamados vértebras. Estos constituyen la columna vertebral. En general, entre más alta sea la lesión en la columna vertebral, más problemas de funciones experimentará la persona [6]. Dado que las primeras siete vértebras en el cuello se llaman cervicales, se le llama a la primera $\mathrm{C} 1$, a la siguiente $\mathrm{C} 2$, hasta llegar a la séptima. Generalmente las lesiones cervicales causan pérdida de las funciones en los brazos y piernas como se muestra en la Fig. 1.
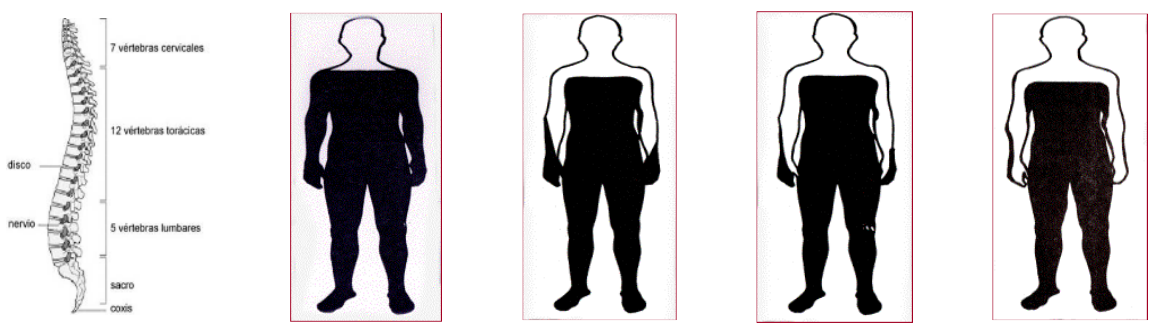

Fig. 1. Descripción de la columna vertebral, así como lesión cervical en C4, C5, C6 y C7 (de Izquierda a Derecha)

\subsection{Silla de rueda motorizada}

Las sillas de ruedas motorizadas están formadas por cinco elementos, la batería que alimenta el vehículo, dos motores que impulsa la silla, el sistema de transmisión y frenos incluidos en las ruedas, el circuito de control y potencia que comanda los motores y finalmente, el joystick, que permiten al usuario dirigir la silla [7],[8]. La mayoría de las sillas de ruedas motorizadas son importadas, de diferentes fabricantes, sin servicio postventa, carecen de información técnica y repuestos para su mantenimiento. Las sillas convencionales con motor tienen un mando que requiere un esfuerzo físico que no todos los usuarios pueden realizar, por ejemplo, los que no pueden mover las extremidades superiores o lo hacen con dificultad.

La silla de ruedas robotizada es una silla de ruedas comercial motorizada que se ha equipado con computadoras y sensores. La silla dispone de dos motores eléctricos de corriente continua que impulsan las dos ruedas traseras (ruedas tractoras). Las dos ruedas delanteras de movimiento libre permiten el giro de la silla. En la actualidad es posible encontrar diversos trabajos en desarrollo de prototipos de sillas de ruedas para personas con lesiones medulares $[9,10]$, sin embargo, la utilización de técnicas para captura de movimiento y reconocimiento de voz en conjunto no son muy utilizadas en este tipo de proyectos. Por otro lado, no funcionan correctamente debido a la cantidad de ruido que llega a haber en un ambiente real y complejo. 


\subsection{Comunicación bluetooth}

Bluetooth es una de las tecnologías más utilizadas para conectar múltiples dispositivos entre sí, se comunica mediante un enlace de radiofrecuencia en la banda ISM de los 2,4 GHz, alcanzando velocidades de $720 \mathrm{~kb} / \mathrm{s}$. Esta tecnología es impulsada por Bluetooth SIG (Special Interest Group) formado por las empresas: Ericsson, Intel, Lenovo, Microsoft, Motorola, Nokia y Toshiba. Uno de los principales objetivos de estas empresas es facilitar las comunicaciones entre equipos móviles, creando así pequeñas conexiones inalámbricas que faciliten la sincronización de datos entre equipos personales [13].

\section{Desarrollo del prototipo de silla de ruedas}

Para el desarrollo del prototipo se utilizó una silla de ruedas comercial motorizada, la cual dispone de dos motores eléctricos que impulsan las dos ruedas traseras; las ruedas delanteras de movimientos libres permiten el giro de la silla. La construcción del prototipo incluye componentes electromecánicos, electrónicos y de software. En la Fig. 2 se pueden observar los detalles técnicos del prototipo: 1) Lector de movimientos del cuello, 2) Dispositivo Hybri-voz, 3) Sensor ultrasónico frontal, 4) Plataforma añadida, 5) Motores, 6) Sensor ultrasónico anti choques y 7) Fuente de energía.

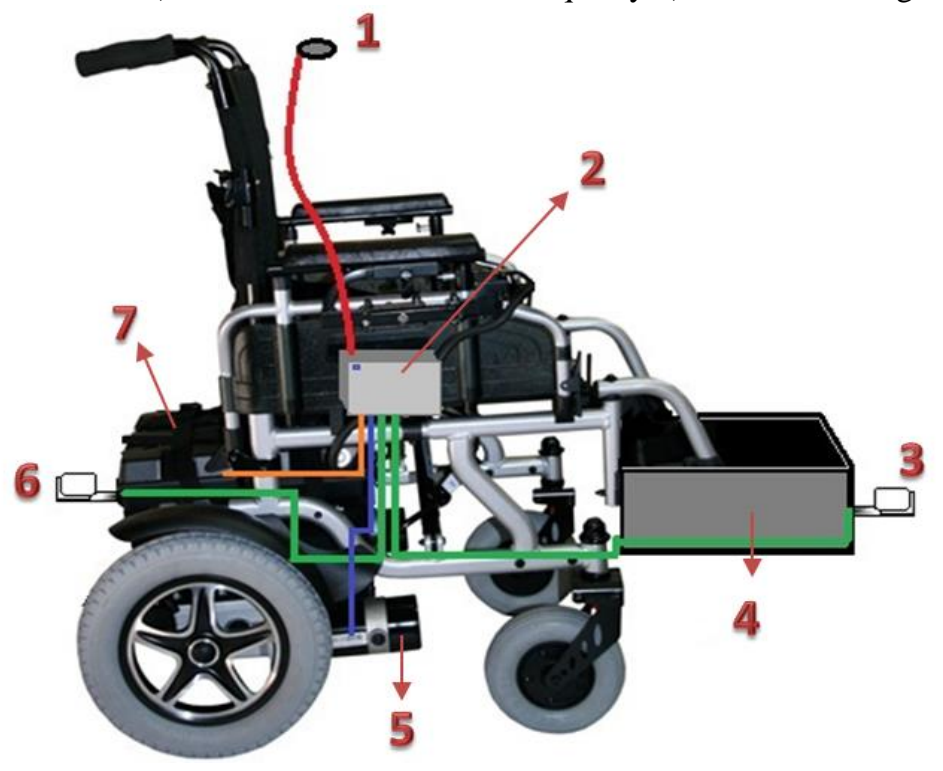

Fig. 2. Componentes del prototipo de silla de ruedas.

\subsection{Componentes electromecánicos}

Dentro del sistema electromecánico del prototipo se encuentran los componentes encargados de suministrar energía eléctrica y de transformar la energía eléctrica en mecánica. Las partes principales del sistema electromecánico son: 
1) Los motores. Considerando la velocidad, autonomía, capacidad de carga e inclinación de pendientes a subir, se decidió incluir dos motores de corriente continua de 12 Volts al prototipo.

2) Las baterías. Para alcanzar la autonomía prevista se decidió la utilización de dos baterías para automóvil (12 Volts), para garantizar 10 horas de uso continuo.

En la Fig. 3 se pueden apreciar la interacción de los componentes electromecánicos y electrónicos del prototipo de la silla de ruedas.

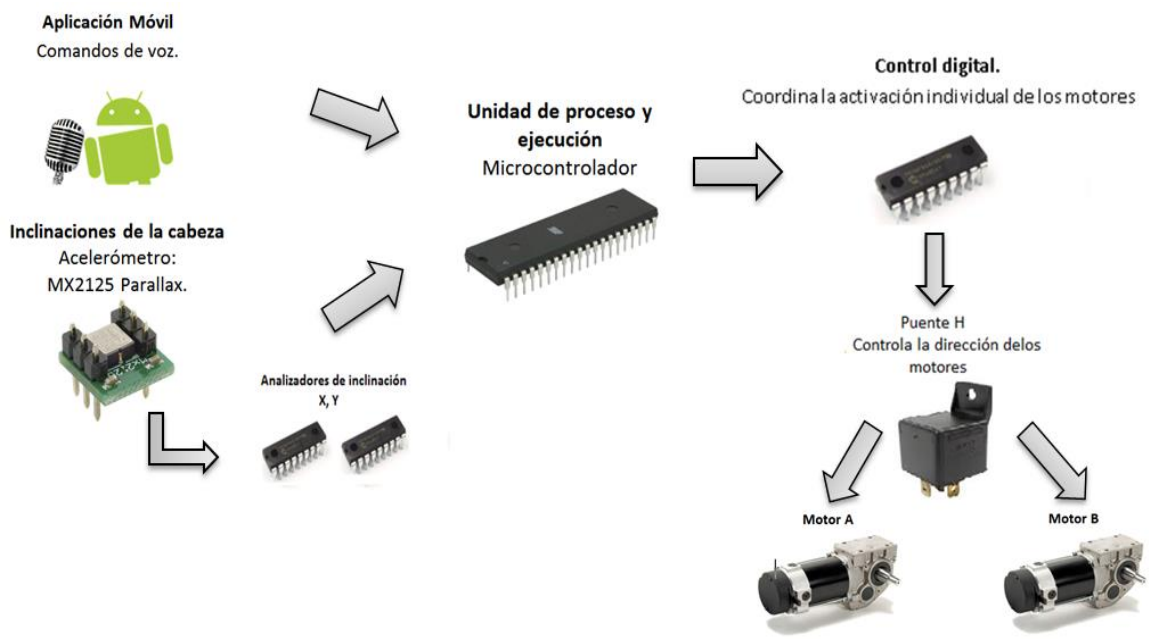

Fig. 3. Diagrama de componentes electrónicos y electromecánicos del prototipo.

También se agregó un tercer microcontrolador esclavo que recibe información del PIC maestro y envía pulsos eléctricos a un segundo módulo ubicado en la parte inferior izquierda de Hybri-voz; este módulo contiene 4 relevadores industriales de alta potencia que están configurados como puente $\mathrm{H}$. Esta configuración permite que sean controlados los dos motores que mueven Hybri-voz en la dirección que el tripulante desee.

Para el control a través de movimientos de la cabeza se utiliza un acelerómetro MX2125, el cual está basado en 2 ejes, y es capaz de medir ángulos de giro, colisiones, aceleración, rotación y vibraciones en un rango de hasta $+/-3 \mathrm{~g}$ sobre los dos. Se incorporaron dos sensores ultrasónicos HC-SR04, para detectar desniveles o la presencia de algún objeto que obstruya el tránsito, en aquellas zonas en las que no se tiene un buen ángulo de visión. Como ejemplo se puede mencionar un movimiento en reversa, cuando uno de estos sensores es activado, se envía una señal al microcontrolador y los motores son detenidos inmediatamente.

\subsection{Aplicación móvil}

Para lograr la comunicación con el dispositivo Hybri-voz a través de comandos de voz, se diseñó una aplicación móvil, y se incorporó un módulo bluetooth HC-05. En la Fig. 4 se puede observar la relación de los elementos que participan en la comunicación entre el módulo HC-05 y la aplicación móvil, así como la interrelación entre ellos. 


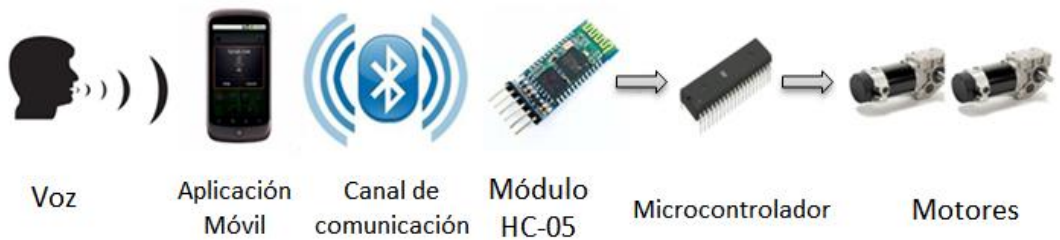

Fig. 4. Elementos de la comunicación entre el módulo bluetooth y la aplicación móvil.

La aplicación móvil se diseñó para el sistema operativo Android, utilizando el reconocimiento de voz de google. En la Fig. 5 se pueden apreciar algunas interfaces de la aplicación móvil. Android incorpora bases de datos de diversos lenguajes, incluyendo el español, estos lenguajes están disponibles para descargar desde las configuraciones del sistema operativo, una vez descargado, esto permitirá realizar el análisis de voz de forma local, sin necesidad de acceder a internet. Esto permite que el procesamiento sea veloz y ejecuta las instrucciones en tiempo real.
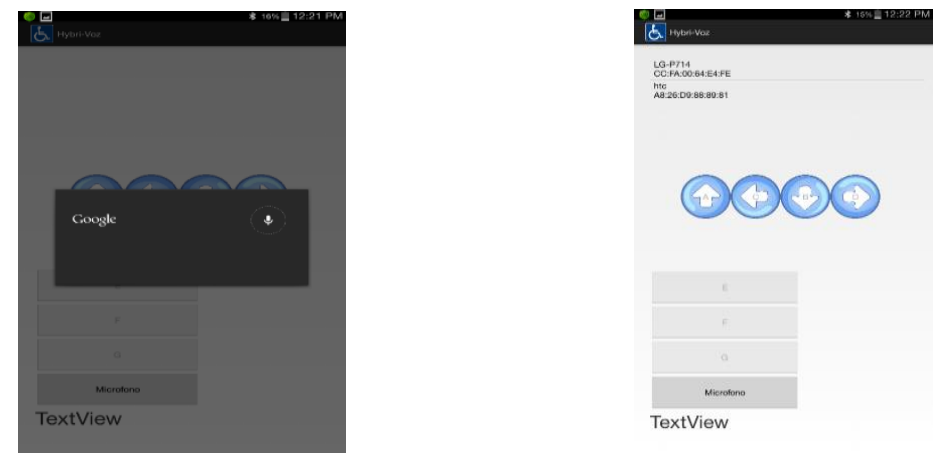

Fig. 5. Interfaces de la aplicación móvil.

La aplicación móvil incluye un conjunto de palabras y sinónimos, como instrucciones para activar el movimiento de la silla de ruedas. Cuando se detecta una palabra correcta se envía una señal vía bluetooth al módulo HC-05, para poder accionar algún movimiento, en caso de que la palabra leída no sea reconocida, el sistema simplemente la ignora y continua leyendo. Para desactivar el micrófono es necesario que el usuario le ordene: "Desactivar micrófono", en este momento el control de la silla de ruedas pasa a ser manipulado por el acelerómetro; sin embargo el micrófono sigue leyendo instrucciones. Para volver a activar los comandos de voz es necesario que el usuario diga: "Activar micrófono". Es importante señalar que el módulo HC-05 funciona como emisor y receptor, por lo tanto la aplicación móvil también puede recibir datos provenientes del dispositivo principal.

\section{Pruebas del funcionamiento del prototipo}

El prototipo de la silla de ruedas fue sometida a diversas pruebas: ascenso y descenso de rampas, detención en rampas, cambios de dirección, movimientos cortos 
en espacios reducidos, largas marchas, cambios del modo de control por voz o inclinación de la cabeza, detección de obstáculos, escalones y desniveles. En la Fig. 6 se pueden observar diversas imágenes con las pruebas realizadas al prototipo de la silla de ruedas.

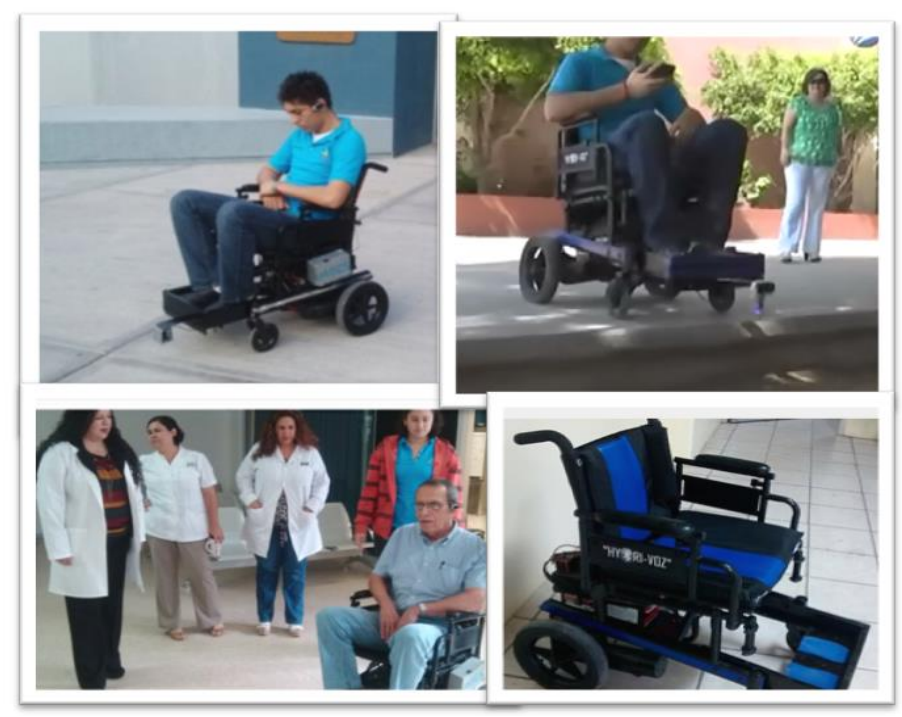

Fig. 6. Pruebas de uso del prototipo de silla de ruedas.

La silla de ruedas respondió favorablemente a cada una las pruebas realizadas:

- Con respecto a los movimientos logrados fueron suaves y precisos.

- Funcionó correctamente en el ascenso y descenso de rampas, así como el detenimiento de la marcha en la propia rampa.

- Las baterías funcionaron correctamente con respecto a la autonomía prevista.

- El control por inclinación de la cabeza funcionó según lo previsto. Al inclinar la cabeza a la derecha o a la izquierda realizaba los giros correspondientes. Al inclinar la cabeza hacia adelante o hacia atrás avanzaba o retrocedía. Mientras la cabeza se mantenía en la posición recta, la silla detenía su marcha.

- El control por voz respondió correctamente a los distintos timbres de voz de las personas que utilizaron la silla.

- Los sistemas electrónicos de seguridad funcionaron correctamente ante la presencia de obstáculos, así como en la detección de escalones y desniveles.

\section{Conclusiones}

El desarrollo de este prototipo, se caracteriza por su bajo costo y eficiencia de funcionamiento. Los resultados obtenidos mostraron un comportamiento estable, lográndose el objetivo de manipular una silla de ruedas motorizada convencional, sustituyendo el Joystick, para ser controlada con inclinaciones de la cabeza o por comandos de voz, implementándose dispositivos de seguridad. 
Todos los componentes electrónicos utilizados en este desarrollo están disponibles en el mercado local, posibilitando una sustitución rápida y económica de estos sistemas. Estos aspectos son fundamentales para el usuario habitual de este medio de movilidad.

Este prototipo, a diferencia de otros dispositivos similares, fue desarrollado con muy poca inversión, lo que lo hace de bajo costo y por consiguiente accesible para personas de escasos recursos. Además otorga la flexibilidad de cambiar el modo de manejo, con el fin de adaptarse a las diferentes necesidades de cada individuo.

Se contempla como una mejora a futuro, que la aplicación móvil pueda recolectar datos adicionales que permitan llevar un monitoreo y análisis de otros elementos que se pudieran añadir al dispositivo principal (Ejemplos: Oxigenación, Ritmo cardiaco, temperatura, estado de los motores, entre otros).

\section{Referencias}

1. Organización Mundial de la Salud: http://www.who.int/disabilities/world_report/2011/es/

2. Instituto Nacional de Estadística, Geografía e Informática (INEGI): http://cuentame.inegi.org.mx/poblacion/discapacidad.aspx?tema=P

3. Organización Mundial de la Salud: http://www.who.int/disabilities/technology/es/

4. Centros para el control y la prevención de enfermedades (CDC): http://www.cdc.gov/ncbddd/Spanish/disabilityandhealth/types.html

5. Dirección General de Educación Especial: http://eespecial.sev.gob.mx/difusion/motriz.php

6. Lesión Medular: http://www.lesionmedular.org

7. Rigano, C.D., Bottani, J.P., Romano, A., Moro Zubillaga, R. Orqueda, O.: Sistema de control de una silla de ruedas motorizada para personas cuadripléjicas. Universidad Tecnológica Nacional, Facultad Regional Bahía Blanca (2000)

8. Ding, D., Cooper, R.A.: Electric powered wheelchairs. Control Systems magazine, IEEE, Vol. 25, pp. 22-34 (2005)

9. Mazo, M., Rodríguez, F.J., Lázaro, L., Ureña, J., García, J.C., Snatiso, E., Revenga, P., Jesús, G.J.: Wheelchair for Physically Disabled People with Voice. Ultrasonic and Infrared Sensor Control, Autonomous Robots, Madrid España, Kluwer Academic Publishers, Boston, pp. 203-224 (1995)

10. Alcubierre, J., Minguez, J., Montesano, L., Montano, L., Saz, O., Lleida, E.: Silla de Ruedas Inteligente Controlada por Voz. Universidad de Zaragoza, España, Zaragoza, España (2005)

11. Cabrero, J.: TICs para la igualdad: la brecha digital en la discapacidad. Anales de la Universidad Metropolitana, Vol. 8, No. 2, pp. 15-43 (2008)

12. Patton, B.L.: PIC Programming for the Impatient: The MikroBasic Edition. Publisher Robodyssey Systems (2005)

13 García-Serrano, A.: Redes Wi-Fi. Anaya Multimedia-Anaya Interactiva (2008) 